\title{
Air quality in Buenos Aires Province, Argentina
}

\author{
N. Quaranta ${ }^{1}$, M. Caligaris ${ }^{1}$, M. Unsen ${ }^{1}$, G. Rodríguez ${ }^{1}$, H. López ${ }^{1}$, \\ C. Giansiracusa ${ }^{1} \&$ P. Vázquez ${ }^{2}$ \\ ${ }^{1}$ Universidad Tecnológica Nacional, Facultad Regional San Nicolás, \\ Argentina \\ ${ }^{2}$ Universidad Nacional de La Plata, Centro CINDECA, Argentina
}

\begin{abstract}
Studies of different gaseous contaminants and particulate matter were made in several cities of the Buenos Aires Province in Argentina. These cities have noticeable differences in relation to the number of inhabitants, vehicular density, industrial activities, etc. They are La Plata, Bahía Blanca, Mar del Plata, Pergamino and San Nicolás, among other towns.

In each city, continuous monitoring equipment with electrochemical sensor technology was installed, in order to determine the NOx, $\mathrm{CO}, \mathrm{HC}, \mathrm{SO}_{2}$ and $\mathrm{O}_{3}$ concentration.

The particulate matter samples were picked up using high volume equipment and daily concentrations corresponding to total suspended solids (PM) were determined by a gravimetric method. The particles were characterized by optical microscopy, scanning electron microscopy (SEM) and electron diffraction analysis X-ray (EDAX). The results obtained showed a direct relationship between the type and quantity of the present particles and the general characteristics of the towns.

The present study is part of the research project "Study of the Air Quality in Buenos Aires Province", financially supported by the National Agency of Scientific and Technological Promotion, Argentina.

Keywords: air quality, air pollutants, particulate matter.
\end{abstract}

\section{Introduction}

Nowadays the increasing impact of human activities on the environment is one of the worries of the international community. These impacts are usually studied 
locally but it is becoming more frequent to take into account the global effects on human and environmental health.

Science is the key to identify the nature and scale of the impacts and to establish the need for regulatory decisions in the processes. Only if there is a continuous improvement of the knowledge on environmental pollution and its control possibilities will the impacts on the ecosystems be predicted adequately and the effects of the local, regional, national and international changes be evaluated properly.

The "Study of the Air Quality in Buenos Aires Province" project has been designed to carry out the study of the air quality in different cities in Buenos Aires Province, Argentina, in order to build a representation of pollution levels, to determine the influence of the different industries and vehicles contributions, the different geographies, meteorological conditions, etc. and to establish the applicability of different diffusion models that allow to predict future situations.

Buenos Aires is the second largest province in Argentina and congregates the third part of its population.

The most important result to achieve is firstly the characterization of air quality in Buenos Aires Province, secondly the local government awareness of the situation, and of the people of the different areas where the direct measures are taken, and lastly an intense diffusion of the environmental issue locally and provincially together with formation of human resources. All these achievements will be regarded as the beginning of an environmental monitoring and controlling process in Argentina, and the start of collective awareness leading to a modification of individual actions. This would bring about an optimal use of the natural resources and a minimization of contamination.

The objective of the present work is to study the air quality in Buenos Aires Province by means of the contaminants analysis in different points selected for their position and population density, and to establish concentration patterns of the studied contaminants. Not only densely populated areas and their industrial surroundings were studied, other areas with low and no density were also considered. The present situation of air contaminants was determined.

\section{Experimental}

Measurements were made in different cities of Buenos Aires Province. The pollutant levels established in Argentine norms for ambient air quality follow the values fixed by the Environmental Protection Agency of United States [1].

The determined gases were nitrogen oxides $\left(\mathrm{NO}_{\mathrm{X}}\right)$, sulphur dioxide $\left(\mathrm{SO}_{2}\right)$, carbon monoxide $(\mathrm{CO})$, hydrocarbons $(\mathrm{HC})$, and ozone $\left(\mathrm{O}_{3}\right)$. These gases were measured by a monitoring system which included a remote station located in each city and a Central Station which received the data by means of cell phone system located in San Nicolás Regional Faculty. The measurements were performed by electrochemical sensors technology. The complete description of the monitoring system, including the sensors measurement ranges sensitivity to each pollutant was given in a previous work [2]. 
The presence of particles was also studied, determining concentrations and size distribution and analyzing their physicochemical characteristics. For this purpose, air samples were collected using high volume equipment. The mass of particle samples collected was determined by using a four decimal balance. First the clean dry filter is weighed, then after 24 hours, the filter with the collected sample is dried again and stored in a sterile Petri dish until it is weighed again.

The samples were observed by optical and scanning electron microscopies. The optical observations were made through an Axiotech Zeiss microscope with annexed Philips video camera. The scanning electron microscopy (SEM) analyses were carried out through a Philips 515 scanning electronic microscope with an EDAX X-ray detector.

The contaminants aggressiveness depends mainly on their concentration in the atmosphere. Consequently, the pollution level in a region does not depend solely on the sources but also on the dispersion in the air of the polluting agents. This is directly related with the meteorological conditions of the area, specially winds, rains, and temperature profiles of the surrounding atmosphere, parameters that were also determined in the present study, by using a weather station Davis Monitor II - USA. The data obtained by the National Meteorological Service were also consulted.

In this study the vehicular pollution was specifically analyzed. For this purpose the monitoring equipments were installed in the cities' centre, in order to determine the contaminants concentration. The number of inhabitants and the vehicular density were analyzed in order to infer the corresponding values for cities with similar characteristics, including geographical ones such as the proximity of the city to the sea, the presence of wind channels, etc.

The studied cities were La Plata, Pergamino, Chacabuco, Mar del Plata, Bahía Blanca, Trenque Lauquen, Olavarría, 9 de Julio, Saladillo and San Nicolás.

\section{Results and discussion}

The first stage of this work involved local studies of air quality in densely populated spots among which are the capital city of the province (La Plata) and other important cities, together with areas which represent zones of medium and low population density. The second stage was the zonal analysis of the results of those local studies. Maps showing the concentration of the different pollutants registered were made.

The evolution of the air quality was performed analyzing the $\mathrm{CO}$ concentration as the most representative one. The other primary contaminants analyzed, without taking into account ozone, showed similar evolutions. The ozone concentration depends not only on the amounts of the precursor gases present but on local and seasonal weather conditions.

\subsection{Local studies of air quality}

The general steps followed for the development of the project in each determined site, within the provincial territory were: 
$\checkmark$ Study of the zone to be analyzed.

$\checkmark$ Determination of the data acquisition places.

$\checkmark$ Assembly of the air quality monitoring stations.

$\checkmark$ Collection of meteorological data.

$\checkmark$ Data acquisition and transmission to the Central Station.

$\checkmark$ Data treatment and results analysis.

The study of the zone implies the analysis of the geographical, historical meteorological conditions, characteristics of the running motor vehicles, social behavior of the local people, local industries, etc. The results of these studies allow to determine the most convenient sites for data acquisition and the most representative hours to take into account for the analysis depending on what is to be evaluated, whether the vehicular contributions, the industrial contributions, the seasons differences, etc.

Table 1: $\quad$ Some characteristics of the studied cities.

\begin{tabular}{|c|c|c|c|}
\hline City & $\begin{array}{l}\text { Inhabitants } \\
\text { Number }\end{array}$ & $\begin{array}{l}\text { Vehicles } \\
\text { Number }\end{array}$ & General characteristics \\
\hline Saladillo & 29,600 & 12,409 & $\begin{array}{l}\text { Agriculture and cattle raising. } \\
\text { Moderate winds. }\end{array}$ \\
\hline $\begin{array}{l}\text { Trenque } \\
\text { Lauquen }\end{array}$ & 40,181 & 17,309 & $\begin{array}{l}\text { Agriculture and cattle raising. } \\
\text { Strong winds. }\end{array}$ \\
\hline 9 de Julio & 45,998 & 20,039 & $\begin{array}{l}\text { Agriculture and cattle raising. } \\
\text { Moderate winds. }\end{array}$ \\
\hline Chacabuco & 45,445 & 20,192 & $\begin{array}{l}\text { Agriculture and cattle raising. } \\
\text { Moderate winds. }\end{array}$ \\
\hline $\begin{array}{l}\text { San } \\
\text { Nicolás }\end{array}$ & 137,867 & 38,723 & $\begin{array}{l}\text { Large number of industries: iron } \\
\text { steel, energy production, etc. } \\
\text { Moderate winds. }\end{array}$ \\
\hline Pergamino & 99,193 & 40,863 & $\begin{array}{l}\text { Agriculture and cattle raising. } \\
\text { Moderate winds. }\end{array}$ \\
\hline Olavarría & 103,952 & 44,054 & $\begin{array}{l}\text { Agriculture and cattle raising, } \\
\text { cement and mineral industries. } \\
\text { Strong winds. }\end{array}$ \\
\hline $\begin{array}{l}\text { Bahía } \\
\text { Blanca }\end{array}$ & 284,776 & 119,646 & $\begin{array}{l}\text { Several petrochemical industries. } \\
\text { Strong winds - Wind channels. }\end{array}$ \\
\hline $\begin{array}{l}\text { Mar del } \\
\text { Plata }\end{array}$ & 564,056 & 218,791 & $\begin{array}{l}\text { Commercial and tourist activities. } \\
\text { Strong winds - Wind channels. }\end{array}$ \\
\hline La Plata & 574,369 & 285,430 & $\begin{array}{c}\text { Commercial and administrative } \\
\text { activities. } \\
\text { Moderate winds. }\end{array}$ \\
\hline
\end{tabular}

In Table 1 general characteristics of the analyzed cities are shown. Data in relation to vehicle numbers were obtained from Argentine Department of the Interior, National Direction of the Vehicle Proprietor Register and municipal information. Inhabitant numbers correspond to 2001 National Census. 
The wind characteristics in Table 1 must be interpreted as follows:

Moderate classification implies winds from calm to moderate, velocity values less than $40 \mathrm{~km} / \mathrm{h}$.

Strong classification implies winds within $40-70 \mathrm{~km} / \mathrm{h}$.

This classification is taken as a simplification of the known Beaufort Scale. The presence of wind channels corresponds to those cities that have tall buildings and are located near the sea.

In previous works the air quality in San Nicolás [3, 4], and Mar del Plata $[5,6]$ and the particulate matter in San Nicolás, Vicente López and Coronel Suárez [7] were analyzed in detail. An important influence of different factors on the pollution levels was established in these studies. These factors are: local social and commercial activities, economic situation, relative location with regard to the sea, wind channels formation, vacation periods, seasonal differences, etc.

The commercial activities are an important item to be considered, as regards the standard contamination levels. The CO pollutant level established in Argentine air quality norm is $9 \mathrm{ppm}$ which corresponds to the average of a period of eight hours, taken between 8:00 and 16:00. This period was established considering the situation of the big cities where the commercial and administrative activities are developed without interruption during this time. This situation doesn't occur in towns located in the inner of the province or in small towns, where the activities stop at 13:00 and begin again at 16:00. So, for comparative purposes, in these places the values of the $\mathrm{CO}$ concentrations have to be calculated otherwise. In the present work the $\mathrm{CO}$ concentration values were calculated taking into account the eight hours of maximum values determined in each analyzed day. In big cities, these two calculation ways give practically the same concentration values.

The most common behaviour observed in the majority of studied cities during working days was the presence of maximum pollution values in two hour bands a day: 12:00 - 13:00 and 20:00 - 21:00. As an example the CO levels determined in Mar del Plata city [6] are shown in Figure 1.

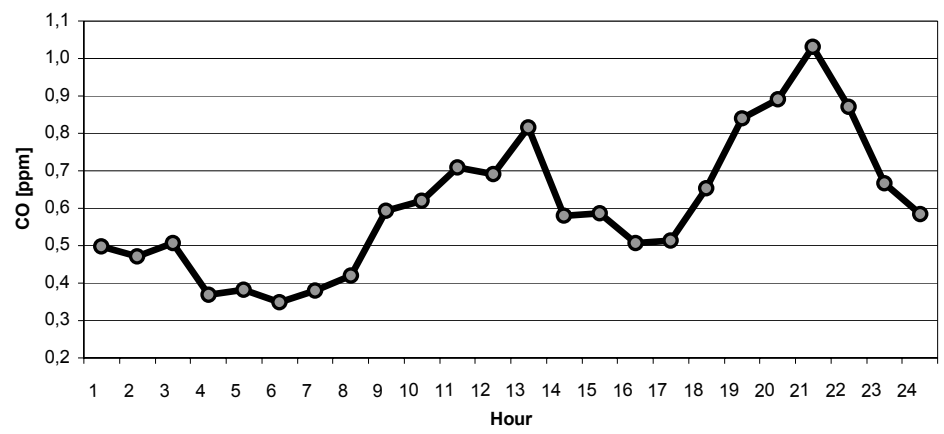

Figure 1: Hourly CO concentrations in Mar del Plata.

The cities which keep daily continue commercial and administrative activities show pollution levels that follow the behaviour presented in Figure 2, with more 
stable values during all hours of daylight, which correspond to the studies made in La Plata city. La Plata is the province capital city and it has an important number of Government and Justice offices in the town centre besides the continuing commercial schedule.

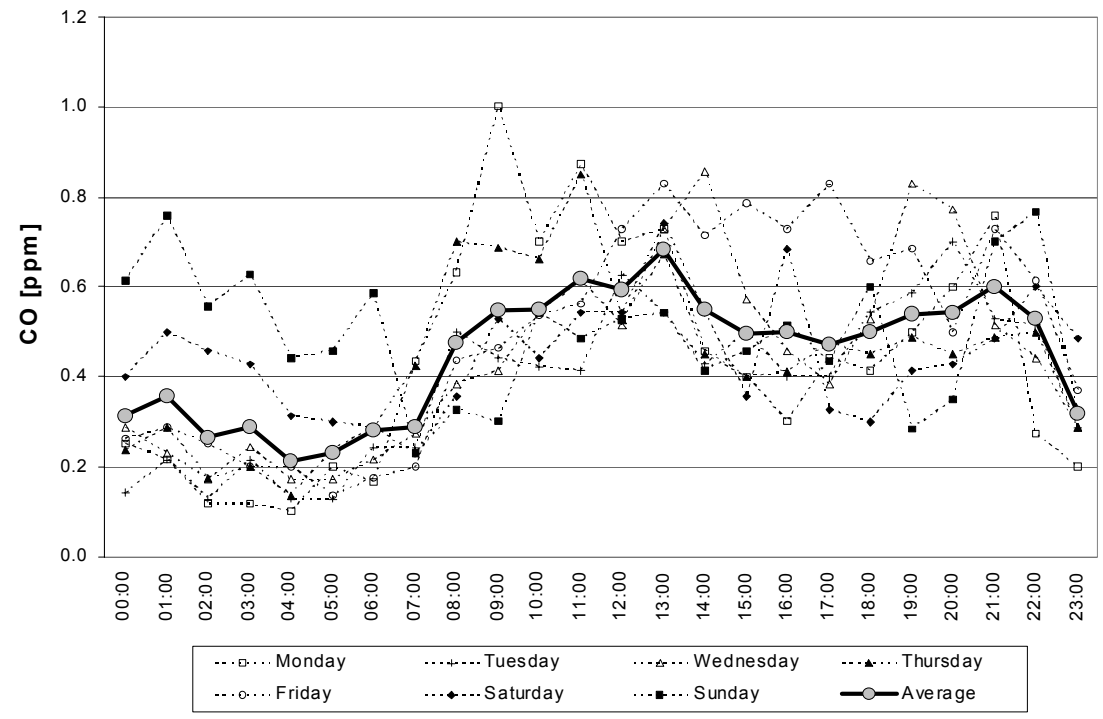

Figure 2: Hourly CO concentrations in La Plata.

The local social activities also produce noticeable differences from the mentioned general behaviour. Pergamino city, for example, shows high CO concentration levels at the last hours of the day practically everyday of the week (Figure 3). This is due to the presence of a bingo hall in the city centre. This is a place where people go to play "bingo" (game in which each player has a card with numbers on, numbers are called out in no particular order and the first player whose numbers are all called out or who has a line of numbers called out wins a money prize). Apart from its own inhabitants Pergamino centre receives during the week numerous visitors from neighboring towns.

The city location is another highly influential factor. For example, the proximity of the cities to the sea in general implies the presence of winds with high velocities and frequencies, and the formation of wind channels in big cities with tall buildings like Mar del Plata. Thus, a comparative study between Mar del Plata and San Nicolás cities is showed in reference [6]. Levels of CO pollutant five times higher in San Nicolás than Mar del Plata were determined, considering similar meteorological conditions, relative orientations between wind direction and streets axes, and similar traffic densities.

All the mentioned factors have to be taken into account in order to avoid the simplification generally observed that considers a direct relationship between pollution levels and vehicular densities. This is rigorously true at a same place with stable meteorological conditions along the analyzed period. 
Management of Natural Resources, Sustainable Development and Ecological Hazards 615

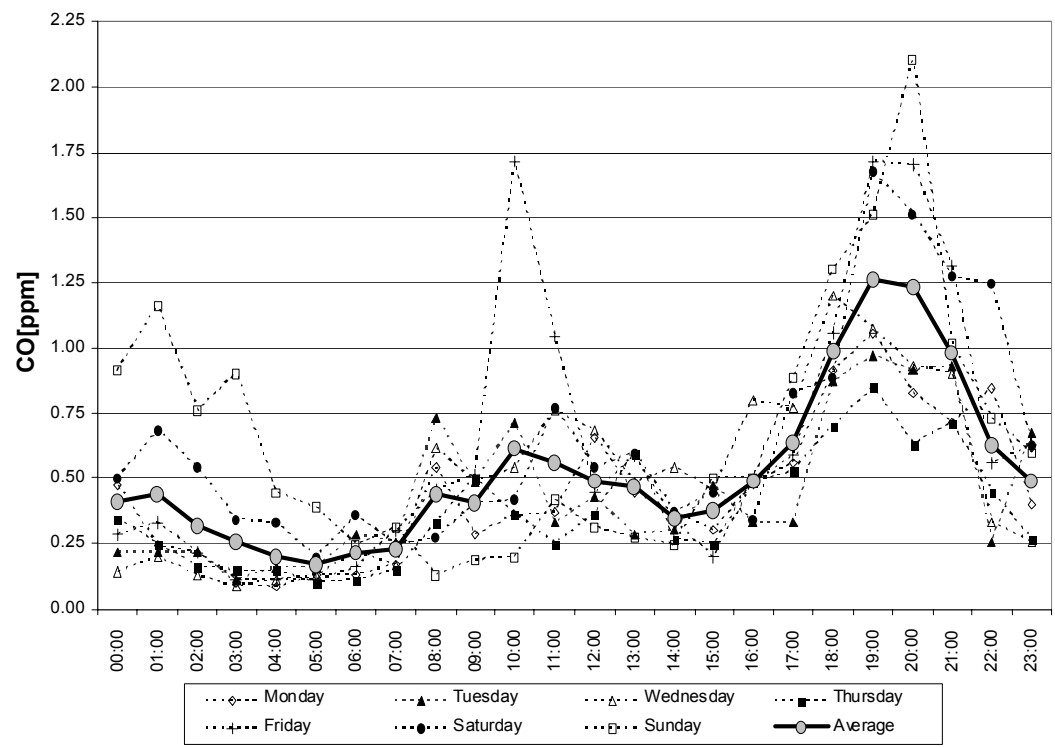

Figure 3: Hourly CO concentrations in Pergamino.

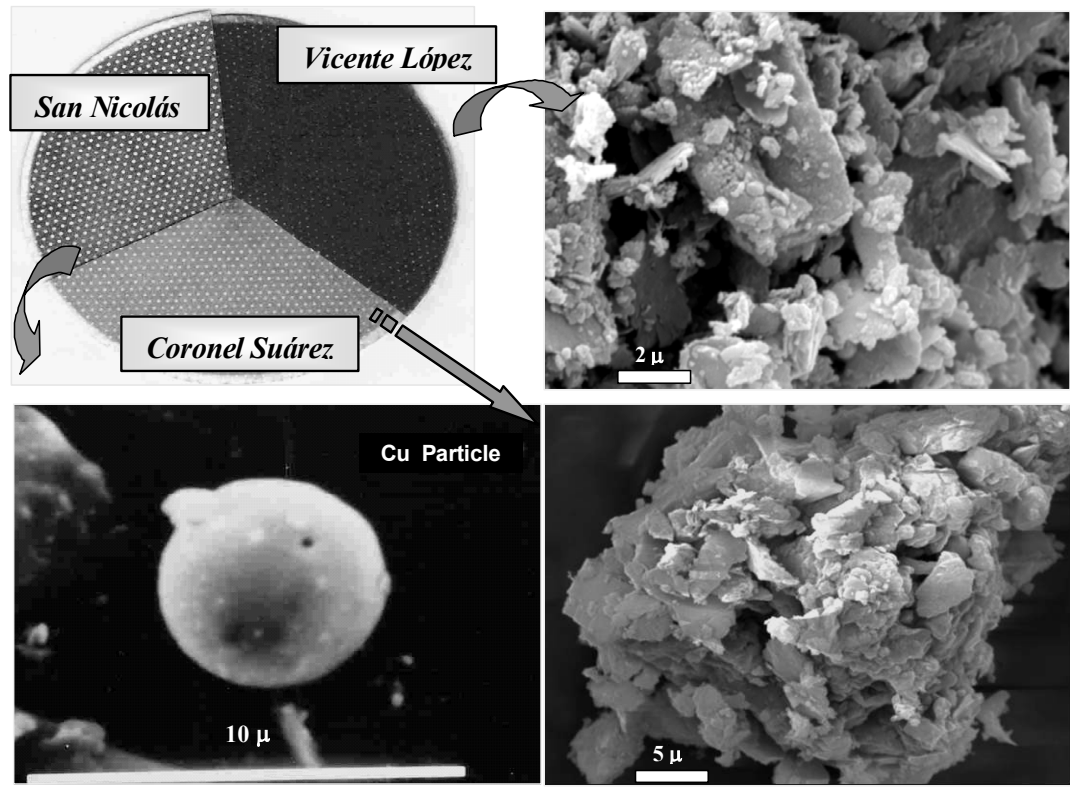

Figure 4: $\quad$ PM characterization in urban, rural and industrial environments.

In relation to the particulate matter analyses a precise detail of the characteristics found in cities with remarkable differences in their main activities is presented in [7]. From it, Figure 4 abstracts the concluding results. 
The PM contaminant shows very different compositions depending on its origin environments: urban, industrial and rural.

In Vicente López PM samples (urban) it is possible to observe the presence of small particles nucleating over bigger ones like a mass of agglomerated particles with an important percentage of carbon.

Coronel Suárez PM analyses (rural) present the typical composition found in atmospheric dust, mainly consisting of earth particle in suspension and biological particles like pollen. The chemical compositions are similar to silicoaluminate compounds like clays and feldspars.

In the case of PM analyzed in San Nicolás (industrial) the present particles are the typical ones of vehicular pollution and also those originated from industrial high temperature processes such as metallurgical, steel or metal mechanics industries, characterized by spherical shapes.

\subsection{Zonal analysis from the results of local studies}

Pollution levels maps were drawn taking into account the contaminants concentrations determined at the sites under analysis.

Figure 5 shows the location of the studied cities within Buenos Aires province territory. The $\mathrm{CO}$ concentration values on the figure correspond to the average of the highest values determined in each analyzed site which were repeated six times or more. The other cities on the figure called "inferred sites" were selected taking into account their general characteristics (vehicles number, meteorological conditions, location in relation to the sea, etc.) and comparing them with the analyzed sites, in order to infer the pollution level. Thus, it is possible to infer similar pollution levels as follows:

-Saladillo: Baradero, Cañuelas, Cnel. Dorrego, Dolores, Médanos, Pigüé, Salto.

-Trenque Lauquen: Bolívar, Gral. Rodríguez, Lincoln, Lobos, 25 de Mayo.

-9 de Julio and Chacabuco: Balcarce, Bragado, Coronel Suárez.

-San Nicolás: Campana, Zárate.

-Pergamino: Escobar, Pilar.

-Olavarría: Tandil.

-Bahía Blanca: Avellaneda, 3 de Febrero.

-La Plata: La Matanza.

The air quality determined by the continuous monitoring stations placed in the different sites of study can be interpreted by means of indexes. In order to reach a better understanding by the population in general an index will be used that classifies the air quality at various levels. In general, the higher the value the poorer the air quality.

One index per contaminant is established according to a concentrations scale that includes the threshold values indicated by regulations. The general index is then determined taking into consideration the individual indexes of each contaminant affected by a factor that considers the danger of such specific contaminant. This quality index will be associated with a pollution level and its influence on health. Thus, pollution levels can be obtained and may be good, moderate, bad, severe or dangerous, representing respectively: almost no 
influence, slight effect in the long term, affections to sensitive organisms or general effect in the short or immediate term.

In the United States, the Air Quality Index (AQI) is used for reporting daily air quality [8]. An AQI value is calculated for five major air pollutants: groundlevel ozone, particle pollution, carbon monoxide, sulfur dioxide, and nitrogen dioxide. An AQI value of 100 generally corresponds to the national air quality standard for the pollutant, and values below 100 are generally thought of as satisfactory. The highest AQI value for the individual pollutants is the AQI value for that day. AQI is usually showed using colors: green-good, yellow-moderate, orange-unhealthy for sensitive groups, and red-unhealthy for all groups. In France the ATMO index, symbolized by a giraffe, is daily calculated referring to four pollutants: sulfur dioxide, nitrogen dioxide, ozone and particulate matter [9]. This index is based on a 10-point scale: 1 for very good air quality, 10 for very bad air quality. Each pollutant is given one of these numbers and the level of the ATMO index is the highest number.

The pollution levels determined in the different cities in this work can be transformed in indexes if the corresponding values are related with the standard of the Argentine regulation, which in the case of the analyzed gas (CO) is $9 \mathrm{ppm}$.

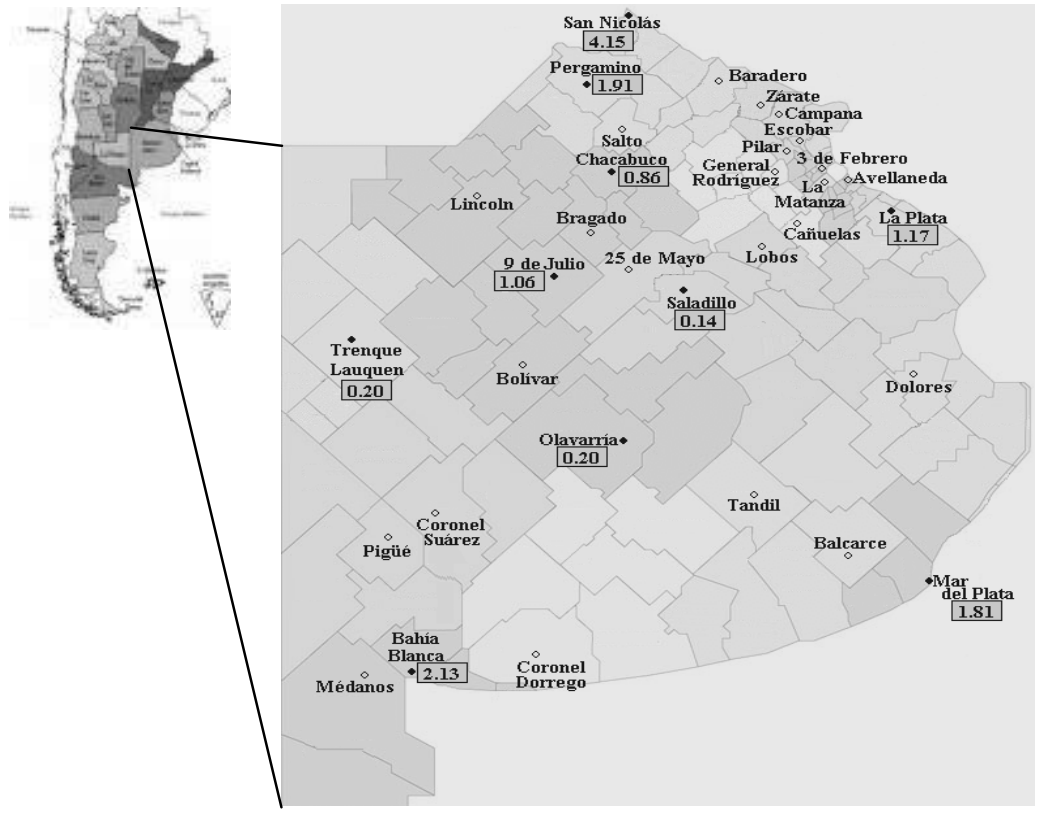

Figure 5: Location of Buenos Aires province cities. •Analyzed sites oInferred sites $\square \mathrm{CO}$ concentration in ppm.

\section{Conclusions}

From the development of this project the influence of different factors on the local pollution levels in several cities of Buenos Aires province was established. 
These factors are social and commercial activities, economic situation, relative location with regard to the sea, among others.

The pollutant concentration levels determined in the different analyzed cities resulted lower than the corresponding ones established in the Argentine regulations.

\section{Acknowledgements}

The authors wish to thank ANPCyT and CIC for the financial support.

\section{References}

[1] Environmental Polity Secretary Decree 3395/96, Law 5965, modified by Resolution 242/97. Argentina.

[2] N. Quaranta and C. Grasselli. Social activities influence on the air quality in San Nicolás City, Argentina. Air Pollution IX, G. Latini \& C.A. Brebbia Eds., pp. 253-261, 2001.

[3] N. Quaranta, C. Grasselli and G. Merizzi. Air quality: the influence of the economic crisis. Air Pollution XII, C.A. Brebbia Ed., pp. 407-414, 2004.

[4] N. Quaranta, C. Grasselli, M. Caligaris and L. Videla. Study of the $\mathrm{O}_{3}$ $\mathrm{NO}_{\mathrm{x}}$ relationship in different periods of the year. Air Pollution XIII, C.A. Brebbia Ed., pp. 279-284, 2005.

[5] S. Mendiara, A. Sagedahl, M. García \& N. Quaranta. $\mathrm{NO}_{2}$ measurements at the bus station area in a big tourist city in Argentina. Air Pollution XIV, J.W.S. Longhurst \& C.A. Brebbia Eds., pp. 251-260, 2006.

[6] N. Quaranta, M. Unsen, M. Caligaris, S. Ringler, S. Mendiara and M. García Air quality in a tourist seashore city during vacations. Urban Transport XII, C.A. Brebbia \& V. Dolezel Eds., pp. 615-621, 2006.

[7] N. Quaranta, M. Caligaris, M. Unsen and G. Pelozo. Characterization of particulate matter from urban, industrial and rural environments. The Sustaintable City I, U. Mander, C. Brebbia \& E. Tiezzi Eds, pp. 379-387, 2006.

[8] http://www.epa.gov/airnow

[9] NOR: DEVP0430272A. Arrêté du 22 juillet 2004 relatif aux indices de la qualité de l'air. 